\title{
Memória e narrativa visual nos álbuns de fotografias oitocentistas das famílias ferreira lage e cavalcanti
}

\section{Memory and visual narrative in photo albums nineteenth century household ferreira lage and cavalcanti}

\author{
Rosane Carmanini Ferraz* \\ rocarmanini@hotmail.com
}

Resumo

O presente trabalho tem como objetivo analisar a coleção de álbuns de fotografias oitocentistas das Famílias Ferreira Lage e Cavalcanti. O estudo é parte de uma pesquisa de doutorado que tem como tema o processo de formação da coleção de fotografias oitocentistas do Museu Mariano Procópio - Juiz de Fora (MG) e sua trajetória de acervo particular a acervo público. Trata-se de uma coleção de 25 álbuns, totalizando cerca de mil fotografias. A grande maioria dos álbuns pertenceu ao colecionador Alfredo Ferreira Lage, fundador do Museu Mariano Procópio e à sua prima, Amélia Machado Cavalcanti, Viscondessa de Cavalcanti. Buscamos caracterizar a coleção, identificando as narrativas visuais contidas nestes álbuns, os principais temas, formatos, técnicas e fotógrafos.

Palavras-chave: narrativa visual, álbum fotográfico, colecionismo.

\begin{abstract}
This paper aims to analyze the collection of nineteenth-century albums of Families Cavalcanti Ferreira Lage and photographs. The study is part of a doctoral research whose theme is the process of forming the collection of nineteenth-century photographs of Mariano Procopio Museum - Juiz de Fora (MG) and its trajectory, from the public collection. It is a collection of 25 albums, totaling about 1,000 photographs. The vast majority of albums belonged to the collector Alfredo Ferreira Lage, founder of the Museum Mariano Procopio and his cousin, Amelia Machado Cavalcanti, Viscountess Cavalcanti. We seek to characterize the collection, identifying visual narratives contained in these albums, the main themes, formats, techniques and photographers.
\end{abstract}

Keywords: visual storytelling, photo album, hoarding. 
Artigos

\section{O colecionismo de fotografias no século XIX e o álbum fotográfico}

O século XIX foi marcado por profundas mudanças históricas, sociais e vasta produção intelectual e artística. Há uma crescente demanda social por imagens. O desejo de captura de imagens é muito anterior, mas foi ao longo deste século que alguns pioneiros desenvolveram variados processos fotográficos. O processo desenvolvido por Daguerre, apresentado em 19 de agosto de 1839, prevaleceu entre os demais, nos primeiros anos da fotografia. A atividade fotográfica ganha fôlego com o desenvolvimento de outras técnicas, que baixaram o custo e possibilitaram a feitura de cópias, como o carte de visite, o carte cabinet e o carte imperial.

Apesar das afirmações acerca do caráter democrático da fotografia, a atividade surge direcionada essencialmente à aristocracia e à burguesia, tanto pela localização dos estúdios quanto pelo preço. A fotografia "revela-se um poderoso instrumento de coesão social, pois oferece às camadas hegemônicas um repertório de imagens comuns que permitem viajar no tempo e no espaço, estabelecer um 'museu imaginário ideal"”. (FABRIS, 2008: 45)

Segundo Ana Teresa Fabris, o desenvolvimento da atividade fotográfica no século XIX passou por três fases características:

\footnotetext{
A primeira etapa estende-se de 1830 aos anos 50 , quando o interesse pela fotografia se restringe a um pequeno número de amadores, provenientes das classes abastadas, que podem pagar os altos preços cobrados pelos artistas fotógrafos (Nadar, Carjat, Le Gray, por exemplo). O segundo momento corresponde à descoberta do cartão de visita fotográfico (carte-de-visite photographique) por Disdéri, que coloca ao alcance de muitos o que até aquele momento fora apanágio de poucos e confere à fotografia uma verdadeira dimensão industrial, quer pelo barateamento do produto, quer pela vulgarização dos ícones fotográficos em vários sentidos (1854). Por volta de 1880, tem início a terceira etapa: é o momento da massificação, quando a fotografia se torna um fenômeno prevalentemente comercial, sem deixar de lado sua pretensão a ser considerada arte. (FABRIS, 2008:17)
}

A difusão dos formatos carte-de-viste e carte cabinet propiciou a criação dos álbuns de retratos de família. Os álbuns passaram a circular amplamente a partir de 1860, se configurando como um instrumento privilegiado para o aumento do consumo de fotografias, tornando-se um indutor do hábito de colecionar retratos que tomou conta do século XIX.

Lima salienta que o álbum fotográfico surge:

(...) atrelado à ideia de coleção, à prática de acumular objetos revestidos de alto valor afetivo e simbólico. Produzidos inicialmente vazios, à espera do arranjo específico que cada história de vida iria dar aos retratos acumulados, os álbuns não tardaram a se transformar em "coleções" montadas por um editor, reunindo fotografias de grandes eventos como as exposições universais, 'souvenirs' de viagens e vistas urbanas de lugares exóticos (1993: 100).

É interessante perceber o álbum fotográfico como necessidade da mentalidade classificatória do século XIX. Além dos álbuns formados em casa, segundo os mais variados critérios, acrescentam-se os álbuns temáticos que reúnem vistas e reproduções de obras de arte.

Estes álbuns eram peças de fabricação artesanal, muitos com encadernação em couro, fechos e cantoneiras de metal ornamentado. Considerado um dos grandes livros do oitocentos, um álbum podia condensar a saga familiar, uma vez que os antepassados falecidos antes do advento da fotografia poderiam ser contemplados através da reprodução desenhos ou gravuras ou pinturas, numa versão visual das árvores genealógicas. (VASQUEZ, 2003). Nos álbuns, as famílias colecionavam, além dos retratos de seus membros, retratos de amigos, da família imperial, de personalidades nacionais e estrangeiras, inclusive artistas, escritores, filósofos, líderes políticos, entre outros.

Nesse sentido, o álbum de retratos podia representar "comunidade "democrática" do visível que, ao mesmo tempo em que nivelava a todos, emprestava a cada um a dignidade que emanava de seus vizinhos de página", consubstanciando uma "comunidade de semelhantes". (HEYNEMANN, RAINHO, e LISSOVSKY, 2005: 202)

A união entre a fotografia e o álbum se constitui como a primeira grande máquina moderna a documentar o mundo e a amealhar suas imagens. "Antes do desenvolvimento das agências e dos arquivos, o álbum e a fotografia-documento funcionaram em simbiose durante quase um século." (ROUILLÉ, 2009: 98) 
No Brasil, o colecionismo de fotografias também contribuiu para o aumento do consumo e troca das imagens, principalmente dos retratos individuais e coletivos. Esse hábito se consolidou como importante meio de fortalecimento dos laços familiares e de sociabilidade entre a elite oitocentista (MUAZE, 2008).

\section{Memória e narrativa visual na fotografia oitocentista: a coleção em foco}

A coleção analisada faz parte do acervo do Arquivo Fotográfico do Museu Mariano Procópio - Juiz de Fora (MG). Trata-se de uma coleção de 25 álbuns, totalizando cerca de mil fotografias. O estudo é parte de uma pesquisa de doutorado que tem como tema o processo de formação da coleção de fotografias oitocentistas do Museu Mariano Procópio e sua trajetória, de acervo particular a acervo público. A grande maioria dos álbuns pertenceu ao colecionador Alfredo Ferreira Lage, fundador do Museu Mariano Procópio e à sua prima, Amélia Machado Cavalcanti, Viscondessa de Cavalcanti. Buscamos caracterizar a coleção, identificando as narrativas visuais contidas nestes álbuns, os principais temas, formatos, técnicas e fotógrafos.

Em 1944, com o falecimento do doador, é elaborado o Arrolamento dos Bens Artísticos, Históricos e Científicos do Museu Mariano Procópio, importante fonte de pesquisa da coleção. Neste período, o MMP já contava com um acervo muito heterogêneo: joias, moedas, medalhas, indumentárias, armas, móveis, pinturas, esculturas, porcelanas, pratarias, cristais, animais empalhados, minerais, livros, documentos, fotografias, gravuras, entre outras categorias de objetos, com forte influência dos séculos XIX e início do XX, conforme o gosto do colecionador. A grande maioria dos álbuns analisados possui número de arrolamento, o que significa que já faziam parte do acervo do Museu Mariano Procópio na ocasião do falecimento de seu fundador.

A coleção é bastante característica do colecionismo de fotografias no século XIX no se refere às temáticas, técnicas, formatos, ateliês e fotógrafos, dialogando em grande medida com outros acervos públicos e particulares deste período.

A origem da coleção de fotografias do Museu Mariano Procópio confunde-se com a própria história da família Ferreira Lage. Há registros de álbuns que pertenceram a Mariano Procópio e Maria Amália Ferreira Lage. Os filhos do casal, Alfredo e Frederico Ferreira Lage, eram fotógrafos amadores e vinculados ao fotoclubismo. A prima de Alfredo e Frederico, Amélia Machado Cavalcanti, Viscondessa de Cavalcanti, também esteve intimamente ligada à cultura visual do século XIX e início do século XX. Foi importante doadora de acervo ao Museu Mariano Procópio, especialmente ao Arquivo Fotográfico, com álbuns de fotografias e cartões postais.

As coleções de Alfredo Lage são oriundas de aquisições em viagens, em leilões e casas especializadas, no Brasil e no exterior, de doações como as da Viscondessa de Cavalcanti e de relações sociais da Família Ferreira Lage com a Família Imperial Brasileira e outras famílias atuantes no período imperial. No que diz respeito à Família Imperial, as fotografias e outros documentos como cartões postais com correspondências e dedicatórias no Arquivo Fotográfico e as cartas, bilhetes e telegramas no Arquivo Histórico do Museu Mariano Procópio, demonstram a proximidade das relações sociais entre a Família Imperial Brasileira, mesmo após a Proclamação da República, e a Família Ferreira Lage e a Família Cavalcanti. Acreditamos que essas amplas redes de sociabilidade possam ter contribuído de forma significativa para a constituição da coleção.

Parte da coleção demonstra ainda ser oriunda do registro das atividades econômicas, como os álbuns da Estrada União \& Indústria de Revert Henry Klumb e Georges Leuzinger, da atuação política e social das famílias Ferreira Lage e Cavalcanti, por meio dos álbuns relacionados às Exposições Universais.

Entre as redes de sociabilidades criadas pela Família Ferreira Lage, podemos mencionar as relações com a Família Velho de Avelar. Um dos álbuns de retratos em formato carte de visite, pertencente à coleção, foi doado pela Família da Baronesa de Muritiba, Maria José Velho de Avellar, filha do Visconde de Ubá, casada com Manoel José Vieira Tosta, barão de Muritiba. A Baronesa de Muritiba era amiga íntima da Princesa Isabel e sua dama de companhia. Residiu por um tempo em Juiz de Fora, onde o marido foi magistrado.

Dentre os principais temas, podemos citar a predominância de retratos e vistas. O retrato foi a versão mais difundida da atividade fotográfica no século XIX. Posar diante da câmera era um ato de invenção de si, colocando o indivíduo em destaque como elemento principal do espaço de figuração da foto. (MUAZE, 2008) 
Artigos

Conforme Ana Maria Mauad, a fotografia, em especial o retrato fotográfico, com sua possibilidade de encenação, inventa uma memória a ser perenizada, uma imagem capaz de criar uma representação ideal para ser lembrada no futuro. Os álbuns de família se configuram como guardiões das tradições, inventadas ou não.

Além de fotografias de membros da Família Imperial e de membros da Família Ferreira Lage e Cavalcanti, os álbuns apresentam fotografias de personalidades, famílias da nobreza europeia, religiosos (Papas, bispos, cardeais, patriarcas, padres, e Alan Kardec) de Napoleão Bonaparte (foto de litografia), atrizes e cantoras francesas, cientistas, intelectuais, filósofos (Rousseau, Kant, Voltaire), músicos (Mozart, Bethovem) e escritores (Cervantes, La Fontaine, Molière, Victor Hugo), numa narrativa imagética da cultura universal, notadamente a cultura ocidental. Muitos dos retratados já eram falecidos quando a fotografia foi inventada. Tornou-se uma prática recorrente por parte dos estúdios a reprodução fotográfica de gravuras e pinturas destes personagens e sua comercialização para fins de colecionismo. Entre os retratados presentes na coleção, estão os chamados "tipos humanos", negros, indígenas, trabalhadores urbanos, personagens do Império TurcoOtomano, tipos com trajes típicos da Grécia, da Suíça, da Hungria, da Rússia, da Áustria, entre outros.
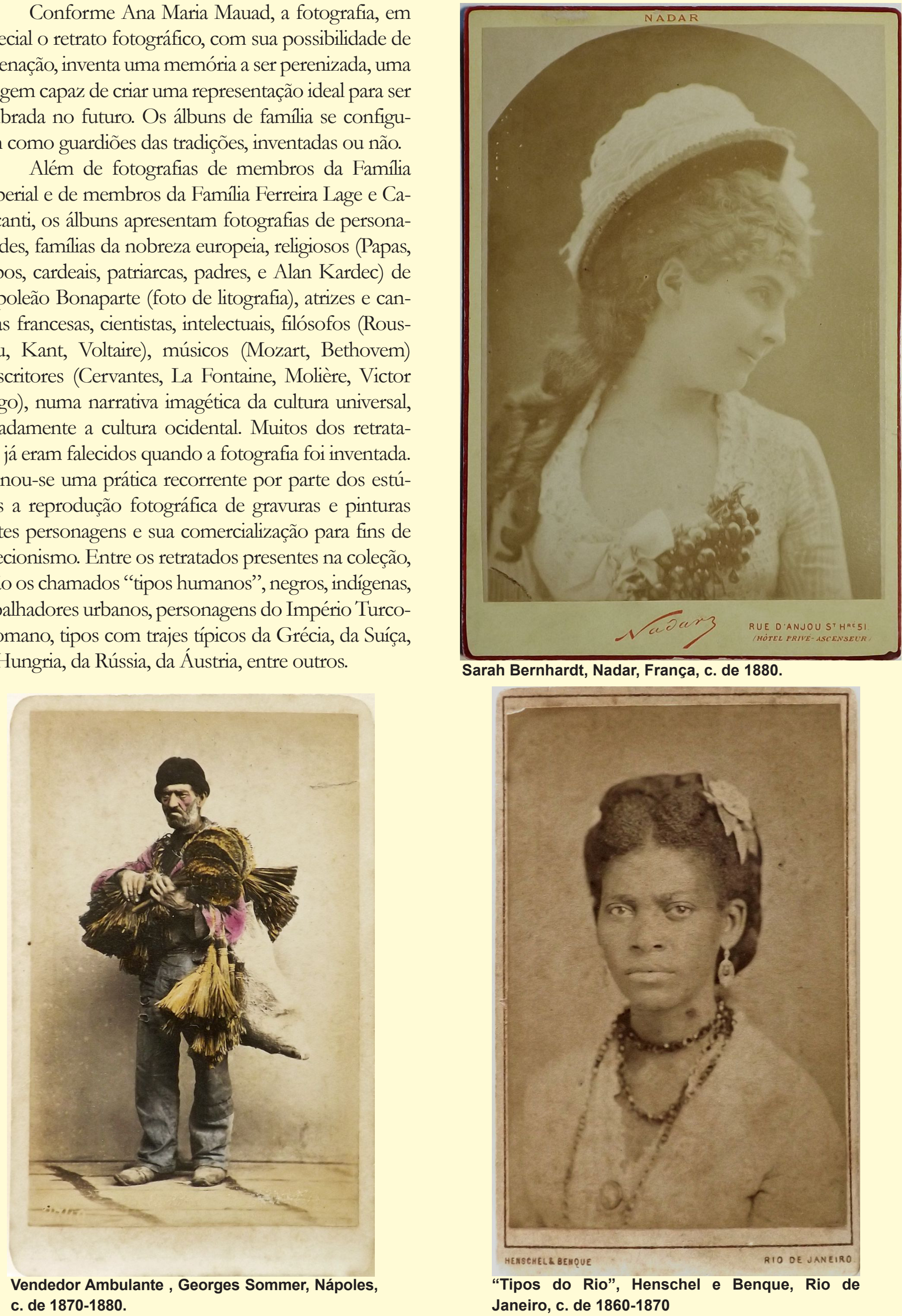

Sarah Bernhardt, Nadar, França, c. de 1880.

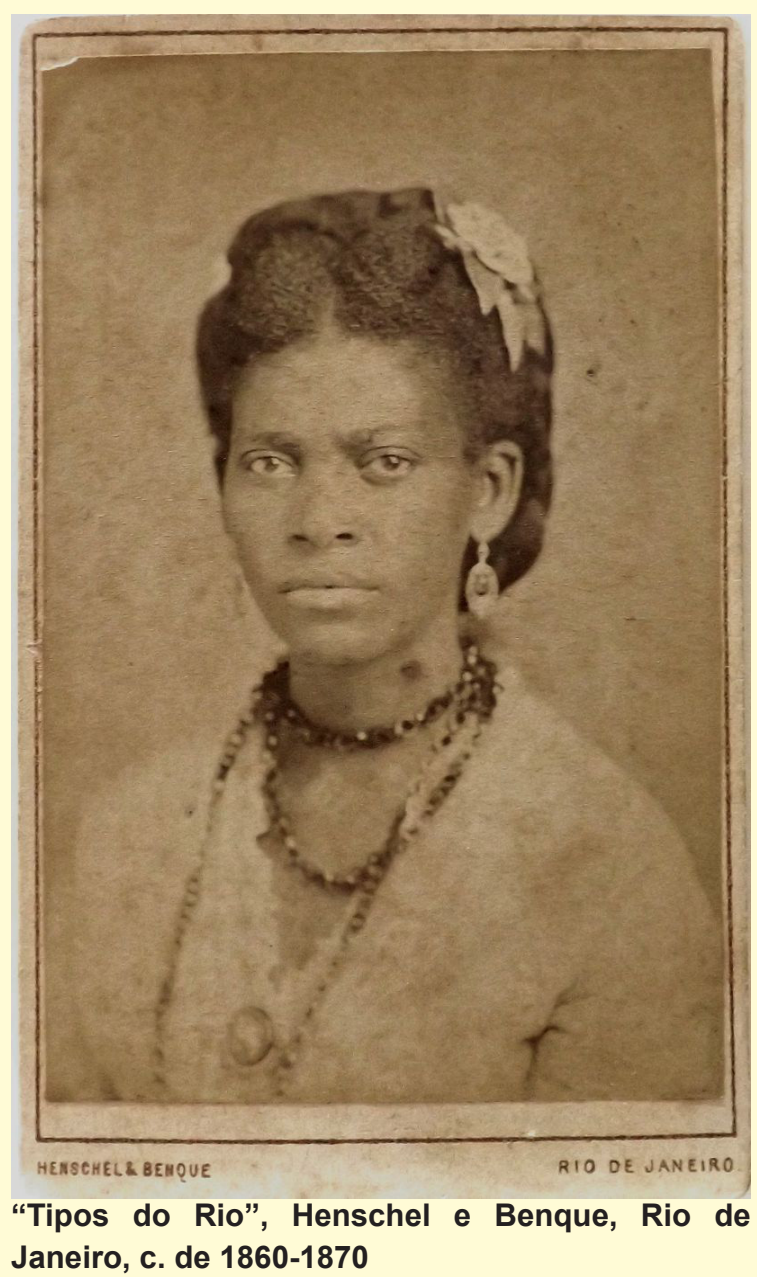


O retrato fotográfico sugere a existência de um indivíduo singular e dotado de interioridade, de um eu que não se perde na sua representação (LAVELLE, 2003). Durante o século XIX e parte do XX, uma sessão de pose em um estúdio fotográfico era um ritual, um acontecimento raro e especial. Nesse sentido, a preocupação com as roupas se justifica, uma vez que a fotografia difunde e cristaliza a posição social e o lugar que o retratado ocupa na sociedade, portanto, a adequação da roupa em relação à posição social do retratado se torna fundamental. "Cartola, fraque, bengala, guarda-chuvas e joias discretas para os homens: vestidos, joias e cabelos indefectivelmente presos para as mulheres são exibidos e valorizados”. (HEYNEMANN, RAINHO e LISSOVSKY, 2005:14)

Entre os álbuns de retratos da coleção, dois se destacam por se tratarem da coleção de fotografias da realeza e da nobreza oitocentista, personagens de um período histórico chamado por Eric Hobsbawn de "era dos impérios", momento marcado por relativa paz na Europa, mas também caracterizado pela existência de países líderes em um processo de dominação e exploração da África e Ásia. Embora o século XVIII tenha assistido à icônica queda da monarquia na Revolução Francesa, que daria origem a fortes movimentos republicanos em todo o mundo em períodos subsequentes, uma grande quantidade de países na Europa ainda era governada por monarcas.

Destacam-se entre as fotografias, os retratos de líderes políticos destronados por movimentos republicanos e que, portanto, representam o último respiro da monarquia em seus países. É o caso de Dom Pedro II, imperador do Brasil entre 1840 e 1889 e de Maximiliano I, imperador do México entre 1864 e 1867. Os monarcas, que eram primos, são os únicos governantes de países latino-americanos presentes no álbum, que é majoritariamente europeu.

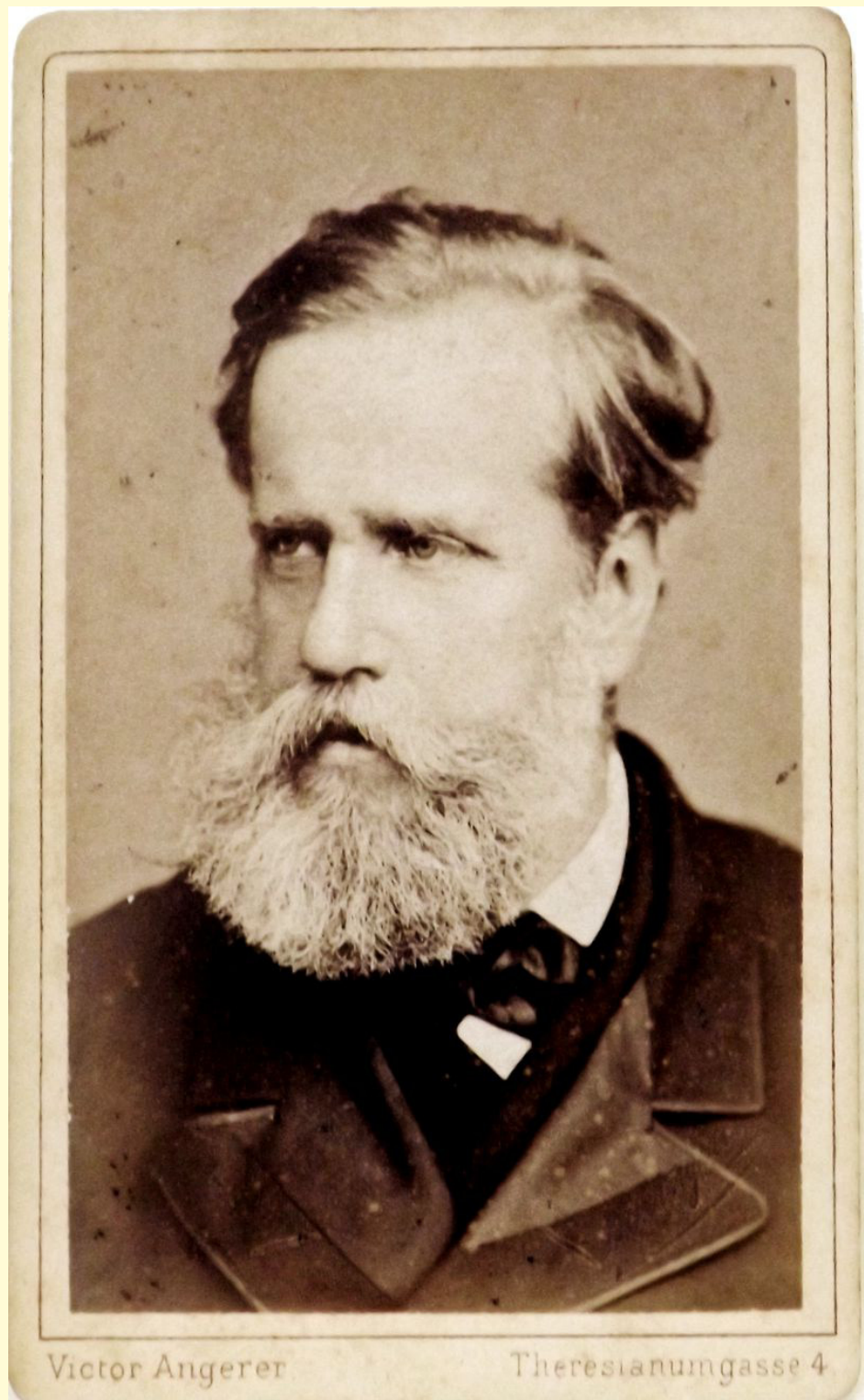

D. Pedro II, Victor Angerer, Viena, c. de 1870.
O álbum narra um importante marco da história europeia: a unificação italiana e alemã. Os países, que se formaram como Estados tardiamente, enfrentaram conflitos políticos e ideológicos na sua constituição como nação. A Itália é representada por ambos os lados de seu intrincado processo de unificação: há no álbum retratos de republicanos como Giuseppe Garibaldi e Giuseppe Mazzini, derrotados na disputa contra os defensores da monarquia, como o Conde de Cavour e o primeiro rei da Itália, Vitor Emanuel II, ambos também retratados no álbum. No caso alemão, existem fotografias do Chanceler Otto Von Bismarck, líder no processo de formação da Alemanha como Estado-Nação e também do Imperador Guilherme I, primeiro imperador da Alemanha unificada.

Por fim, é digna de nota a maneira como os líderes políticos europeus e latino-americanos são retratados nas fotografias. Enquanto membros das casas inglesas e austríacas optaram por ser fotografados em trajes reais, ostentando seus títulos e condecorações, imperadores como D. Pedro II e Napoleão III escolheram o que Pedro Vasquez chama de "look cidadão", vestes comuns que os caracterizavam como indivíduos mais próximos do povo. Era uma estratégia política que tinha como finalidade criar uma maior identificação entre os súditos e sua figura, garantindo assim uma legitimação maior de seus governos. A julgar pela ascensão e pela queda de monarquias ocorrida ao longo do 
Artigos

século XIX, narrada no álbum, o recurso destes monarcas não parece ter sido bem-sucedido. A pompa real pode ser um mecanismo de manutenção do poder.

Além dos retratos, a coleção do Museu Mariano Procópio abriga uma série de álbuns de vistas e paisagens: vistas urbanas do Rio de Janeiro, Salvador, cidades europeias, Itália, Áustria, Polônia, entre outros, além de paisagens do Rio de Janeiro, Petrópolis e panorâmicas.

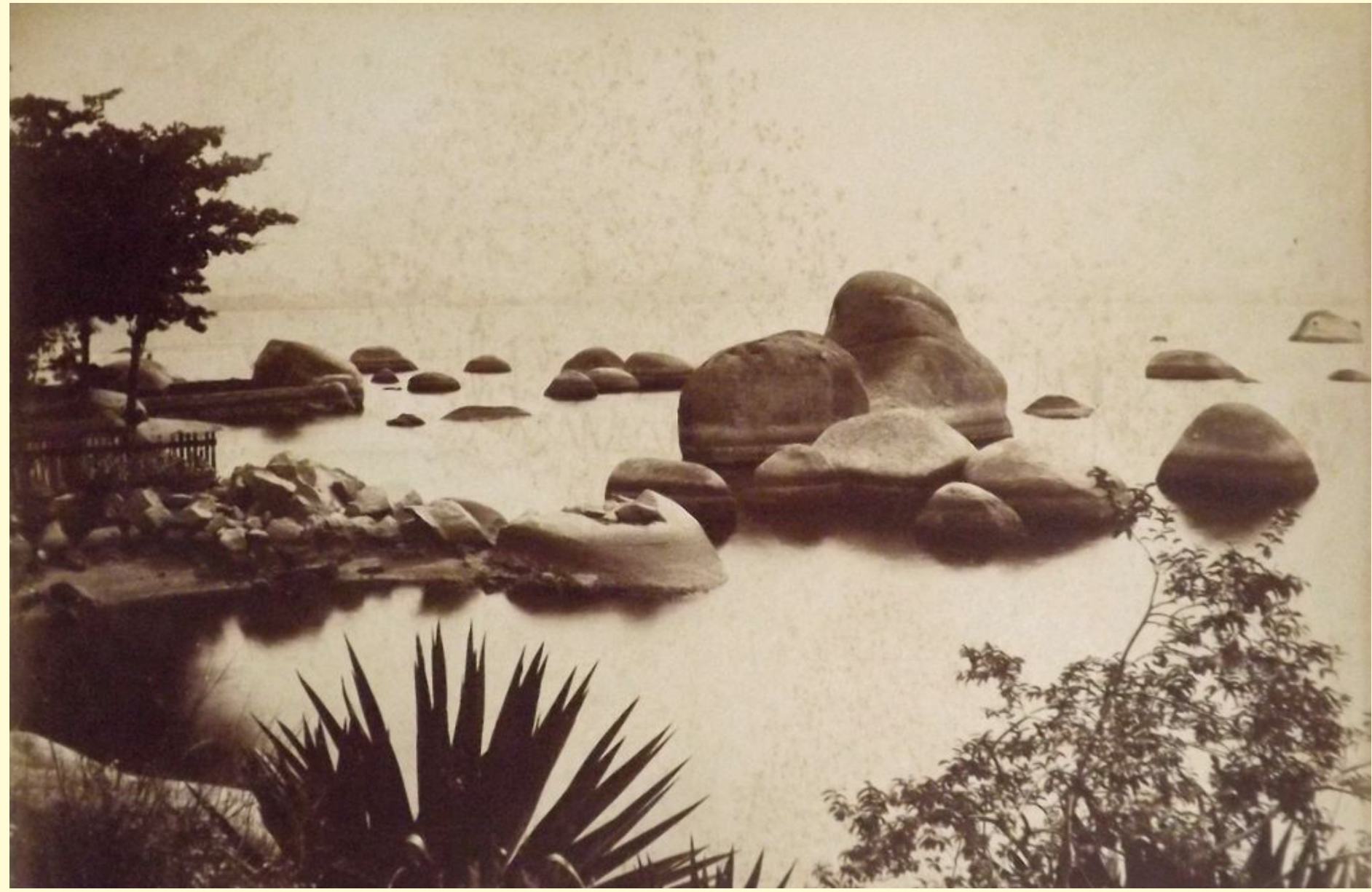

Paquetá, Marc Ferrez, Rio de Janeiro, c. de 1890

Fotógrafos como Klumb, Ferrez e Leuzinger, presentes na coleção, estão inseridos no contexto de construção, por meio de suas imagens, de uma narrativa imaginária do progresso do Brasil. "As conquistas propiciadas pelos avanços do progresso da ciência aliada à técnica eram retratadas com aspectos pitorescos da paisagem natural brasileira na composição de imagens veiculadas em álbuns, vistas avulsas e periódicos ilustrados." As imagens ajudaram "a difundir no imaginário oitocentista brasileiro uma aliança harmoniosa entre o pitoresco promovido pela natureza e o poder do progresso”. (ZENHA, 2006: 366)

Os registros fotográficos denotam a preponderância das imagens urbanas no século XIX, tendo em vista as dificuldades para se fotografar em áreas distantes e de difícil acesso e a quantidade de equipamentos a serem transportados para o local da captura da imagem.

(...) o fotógrafo necessitava de um laboratório químico portátil que correspondia a um equipamento delicado e pesadíssimo, deveria manipular o negativo ainda molhado e revelar a imagem logo após o clichê. Com a consolidação do processo de cópias sobre papel albuminado, a difusão das fotografias de vistas e paisagens em imagens avulsas ou em álbuns completos é incrementada facilitando a viajantes estrangeiros ou visitantes de outras províncias a aquisição de fotografias dos principais prédios e vistas dos mais importantes logradouros da Corte, bem como das diversas belezas naturais da província do Rio de Janeiro." (HEYNEMANN, RAINHO, LISSOVSKY, 2005:18)

No final do século XIX e primeiras décadas do século XX, alguns fotógrafos se dedicaram à produção de álbuns de cidades. 
Para além da estética de cada fotógrafo, que personaliza sua obra, a montagem desses álbuns revelava a força de um padrão fotográfico próprio do tempo em que foram produzidos. Interessado em obter lucro com a venda do álbum, o fotógrafo escolhia as imagens e costurava uma narrativa urbana capaz de tornar vendável o produto de sua criação. Em geral, a sequência de imagens dava ver uma cidade moderna, evoluída e quase sempre higienizada. (BORGES, 2005:84)

As vistas, pautadas numa lógica cultural ocidental, oscilaram entre o ideal de cultura que tinha como cânone maior a civilização europeia, especialmente a França, e a noção de natureza pródiga, exuberante (MUAZE, 2008:118). "Gradualmente a comercialização de vistas vai ocupando um espaço cada vez mais no mercado urbano, atingindo seu ápice nas primeiras décadas do século XX com a "febre dos cartões postais." (LIMA, 2008: 66)

\begin{abstract}
Se o retrato representou para a classe burguesa em ascensão a possibilidade de expressar sua individualidade, as vistas, por sua vez, expressam a conquista do espaço urbano: os edifícios destinados a abrigar as atividades e instituições da burguesia bem como as remodelações urbanísticas segundo a concepção burguesa poderão, graças à fotografia, serem eternizados e divulgados universalmente. (LIMA, 2008: 66)
\end{abstract}

As vistas demonstravam a sintonia entre o fotógrafo e sua época, funcionando como "indutoras da formação de padrões visuais e receptáculo dos símbolos e vetores do imaginário urbano". (LIMA, 2008: 67) Nas vistas

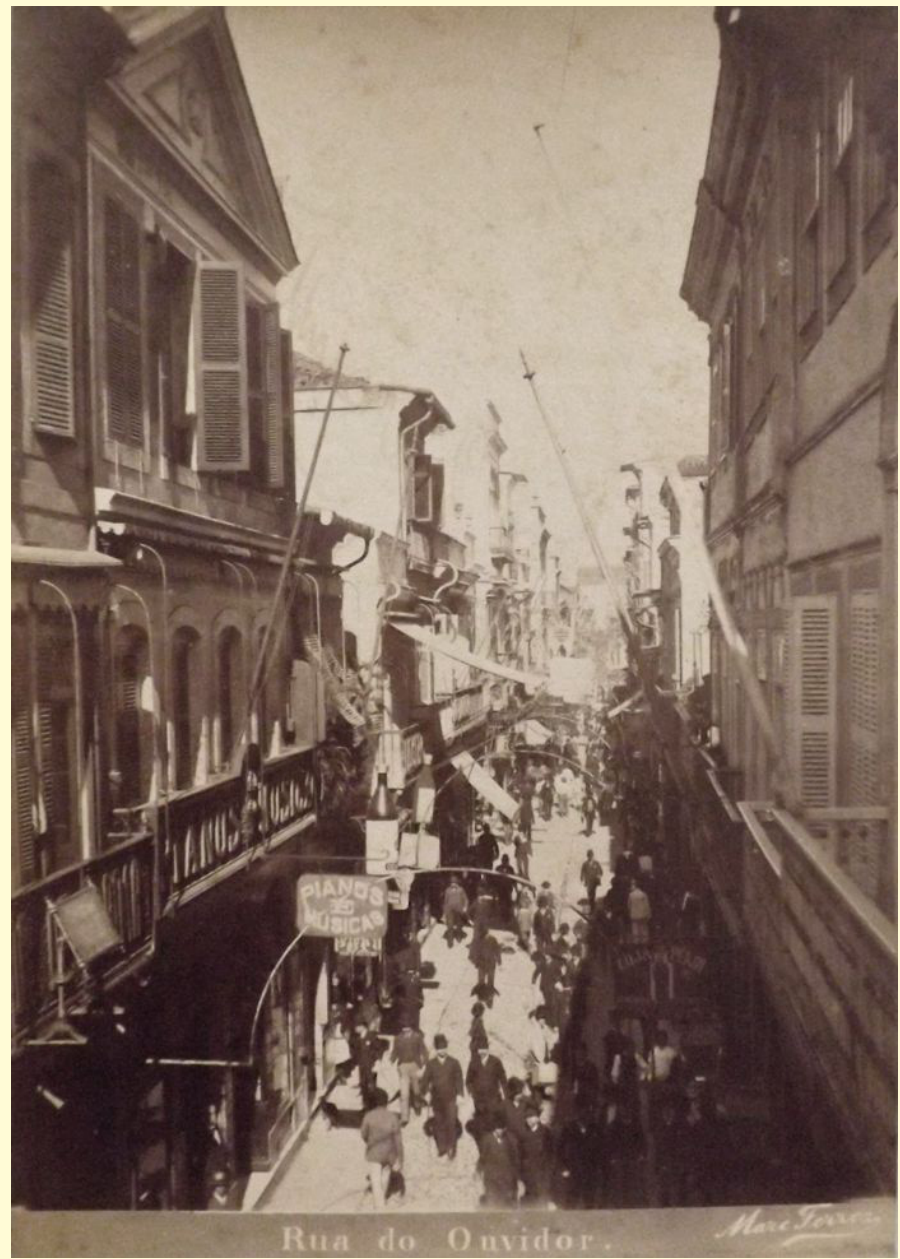

Rua do Ouvidor, Marc Ferrez, Rio de Janeiro, c. de 1890.

que residiam no país, que enviaram as imagens aos amigos e parentes no exterior.

Há ainda na coleção, a fotografia de cunho evidentemente documental, como a documentação da transferência do Meteorito de Bedengó, documentação Policial, os retratos dos salteadores da Sicília e o registro da Estrada União \& Indústria. e paisagens, é possível encontrar os traços da "civilização nos trópicos", inseridas no projeto de construção de uma imagem de nação. Essas imagens atingem significativo grau de circulação sendo editadas em álbuns ou como cartões-postais, publicadas em revistas, livros e almanaques.

Quanto às funções sociais, as vistas urbanas completam o processo de autorrepresentação da sociedade burguesa fazendo com que a fotografia passe a integrar o elenco de suportes aptos à formação e veiculação de seu imaginário urbano. $\mathrm{O}$ universo representado através da variedade de temas - espaços públicos, ferrovias, fazendas de café - compõe a visão de mundo da burguesia na virada do século. (LIMA, 2008: 79)

Os primeiros fotógrafos paisagistas, como Klumb e Leuzinger, presentes na coleção, iniciam suas atividades no Brasil na década de 1850 . No contexto brasileiro, a produção de paisagens com um público mais reduzido, normalmente viajantes e imigrantes

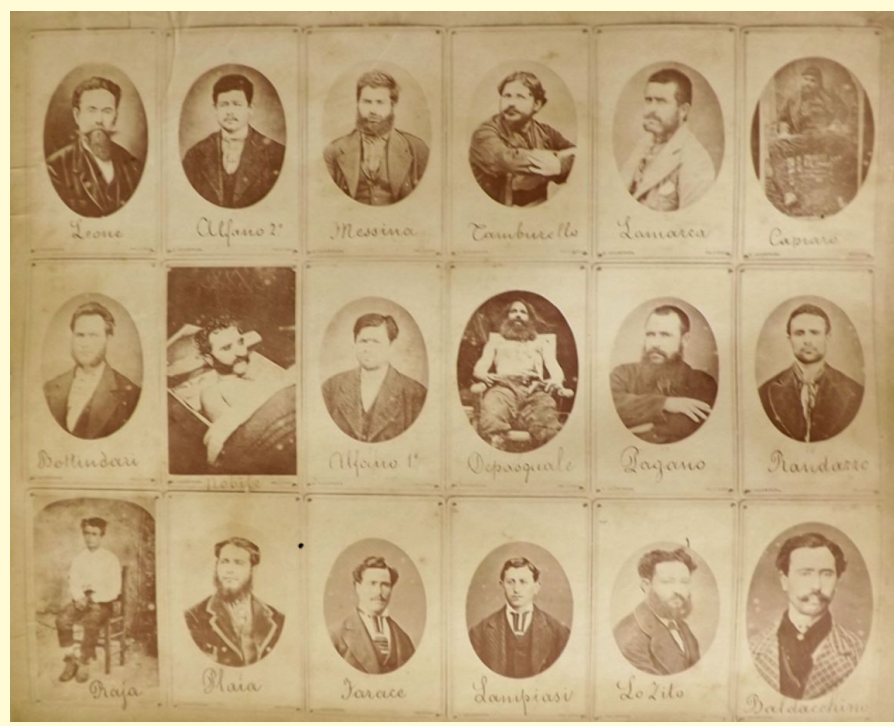

Salteadores da Sicília - Fotógrafo não identificado - s/data 
Artigos

A fotografia em sua função mediadora entre os homens e o mundo é vista como olhos e espelhos da memória. As imagens foram, sobretudo, consultadas, utilizadas, arquivadas. Dentre os diversos usos sociais da fotografia, um dos mais importantes foi o documental. Usada pelas ciências e pela arquitetura como forma de registro, nota-se as múltiplas aplicações da fotografia nas ciências e nas artes.

A documentação fotográfica de expedições de todo tipo (geográficas, geológicas, etnográficas, arqueológica), a cobertura de atividades militares, de construção de estradas de ferro, dos usos e costumes de povos, "muitas vezes em regiões distantes e locais praticamente inacessíveis, exigia do fotógrafo muito desprendimento e coragem em face das inúmeras dificuldades inerentes ao transporte de pesados equipamentos e das limitações dos processos fotográficos da época” (KOSSOY, 1980: 57).

Outra temática muito presente na coleção são os álbuns de Exposições universais, notadamente a Exposição Universal de Paris de 1889 e 1900, retratando cenas de Paris, fachada e interior do Pavilhão Brasileiro, produtos em exposição; Completam as principais temáticas presentes na coleção as panorâmicas, souvenirs de Marienbad, St. Lazare (Veneza), Constantinopla e imagens relacionadas à arquitetura religiosa.

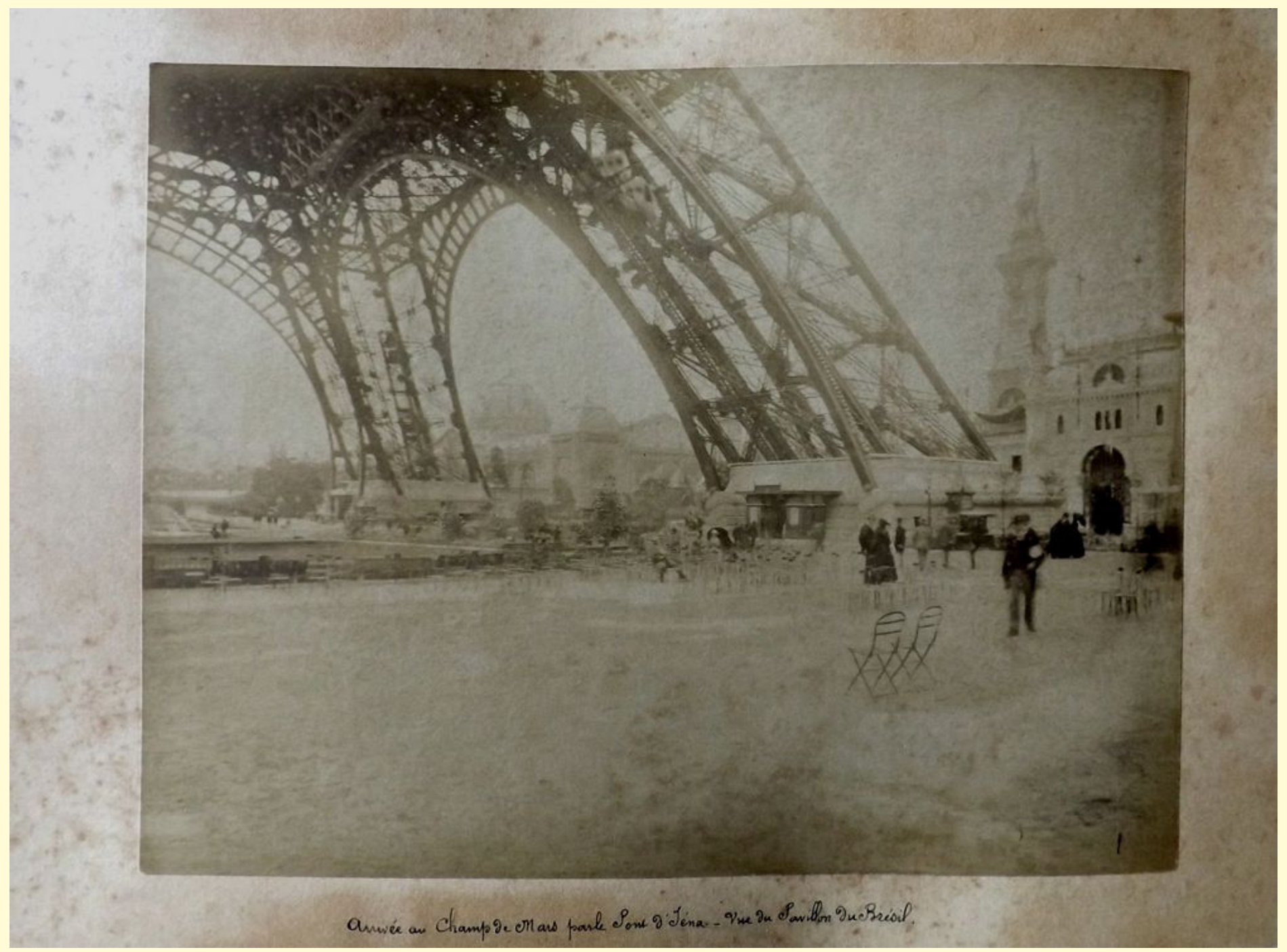

\section{Exposição Universal de Paris, fotógrafo não identificado, 1889}

A ligação entre a fotografia, o desenvolvimento das viagens e da arqueologia só aumentou ao longo da segunda metade do século XIX. Excetuando-se o retrato de estúdio, a arqueologia foi a área mais próspera do comércio de fotografias. Muitos escritores, artistas e arqueólogos viajaram para a Europa e o Oriente Médio nesse período. A literatura, desenhos, pinturas e objetos trazidos dessas regiões alimentavam o gosto do público. O colonialismo, a atividade comercial e a modernização dos transportes, especialmente o marítimo, intensificaram os contatos entre o Oriente e o Ocidente. As exposições universais em grandes capitais da Europa permitiram o contato mais próximo com a cultura das regiões do Oriente (AUBENAS, 2003). A fotografia acompanhou essas transformações históricas.

A grande maioria das fotografias são albuminas em diversos formatos: carte de visite, carte cabinet $\mathrm{e}$ 
pranchas de diferentes formatos. Há ainda fotografias em gelatina. Alguns álbuns apresentam a técnica da foto-pintura, bastante comum no século XIX, desde o período inicial com os daguerreótipos.

Entre os fotógrafos presentes na coleção, podemos citar: Nadar, Pascal Sebah, Giorgio Sommer, Victor Angerer, Sergei Levistky, e a fotógrafa Adele, E. Neudein, entre outros. Empresas fotográficas como a Fratelli Alinari (Florença, - Itália), The London Stereoscope \& Phot. Co.

Os fotógrafos que atuaram no Brasil no período imediatamente após o advento do daguerreótipo, mantiveram, em sua maioria, o caráter itinerante. O Rio de Janeiro era local privilegiado de atuação desses profissionais. Alguns chegaram a fixar seus ateliês na capital do Império. O desenvolvimento econômico, propiciado principalmente pela produção cafeeira, possibilitou a melhoria das condições de acesso ao interior com a criação de estradas de ferro e de rodagem. Esse contexto contribuiu para o aumento da atividade fotográfica no Brasil.

A maioria dos fotógrafos atuantes no Brasil era de origem ou ascendência estrangeira, como Insley Pacheco, Marc Ferrez, R. Henry Klumb, Georges Leuzinger, Jose Ferreira Guimaraes, Alberto Henschel, entre outros. A coleção de álbuns oitocentistas do Museu Mariano Procópio abriga exemplares de todos os fotógrafos acima citados.

A partir da análise da coleção, podemos inferir que o colecionismo da família Ferreira Lage demonstra coerência com sua formação europeia e a mentalidade de seu tempo. Como colecionador, Alfredo Ferreira Lage pode ser entendido como o guardião das memórias da família. Nesse sentido, não é uma mera "motivação individualizada que leva o colecionador a procurar, investigar, encontrar e conservar seus bens preciosos. Ele está imbuído de um papel que lhe confere o direito e também a obrigação de cuidar da memória do grupo familiar”. (BARROS, 1989: 38)

As trocas de fotografias e doações destes documentos ajudam a compreender as formas de ser e pensar do século XIX, assim como permitem compreender as complexas redes de sociabilidade do período e as práticas de autorrepresentação da elite oitocentista. Uma parte das fotografias e cartões postais da coleção foi autografada e/ou contém breves comunicações, o que demonstra o uso social dessas imagens neste período. A análise dessa documentação é uma importante ferramenta de compreensão da tessitura dessas redes das famílias da elite no século XIX e início do século XX.

O estudo pretende propiciar maior visibilidade para a coleção, contribuir para a difusão desses documentos e para o desenvolvimento da produção historiográfica acerca dos usos sociais da fotografia. O estudo da arquitetura das relações sociais, da relação entre as redes de sociabilidades da família Ferreira Lage e formação da coleção de fotografias oitocentistas no acervo do MMP busca contribuir para a compreensão da fotografia oitocentista, para a análise dos usos sociais da fotografia na construção de redes de sociabilidade e do gosto e das características do colecionismo das famílias da elite brasileira do século XIX.

A coleção de álbuns de fotografias oitocentistas do Museu Mariano Procópio é bastante ilustrativa da evolução histórica da técnica fotográfica, além de ser exemplar no que tange o colecionismo de fotografias no período. Esta coleção pode contribuir para a construção uma nova história da fotografia oitocentista no Brasil, a partir do levantamento do acervo existente nas instituições que preservam coleções fotográficas.

Estes registros iconográficos são importantes fontes de estudos relacionados às mais diferentes áreas do conhecimento. Marcada pela diversidade, a fotografia é fruto de um determinado contexto social que a produziu, ou seja, está intrinsecamente relacionada aos valores, costumes e gosto da sociedade desta época.

\section{Referências}

AUBENAS, Sylvie. Viagens pela fotografia no século XIX: a coleção do Imperador Pedro II. In: De volta à luz: fotografias nunca vistas do Imperador. São Paulo, Rio de Janeiro: Banco Santos; Fundação Biblioteca Nacional, 2003.

BARROS, Myriam Moraes Lins de. Memória e Família. Estudos Históricos, Rio de Janeiro, vol 2, n. 3, 1989, p. $29-42$.

BORGES, Maria Eliza Linhares. A história-conhecimento e o documento fotográfico. In: História \& Fotografia. Belo Horizonte: Autêntica, 2005, p. 75-109. 
Artigos

FABRIS, Annateresa. A invenção da fotografia: repercussões sociais. In: FABRIS, Annateresa. (org.) Fotografia: usos e funções no século XIX. São Paulo: Editora da Universidade de São Paulo, 2008, p. 11-37.

. O circuito social da fotografia: estudo de caso I. In: FABRIS, Annateresa. (org.) Fotografia: usos e funções no século XIX. São Paulo: Editora da Universidade de São Paulo, 2008, p. 39- 57.

HEYNEMANN, Claudia Beatriz; RAINHO, Maria do Carmo Teixeira; LISSOVSKY, Maurício. Retratos Modernos. Rio de Janeiro: Arquivo Nacional, 2005.

KOSSOY, Boris. Origens e expansão da fotografia no Brasil. Rio de Janeiro: Funarte, 1980.

LAVELLE, Patrícia. O espelho distorcido: imagens do indivíduo no Brasil oitocentista. Belo Horizonte: UFMG, 2003.

LIMA, Solange Ferraz de. Espaços Projetados: As representações da cidade de São Paulo nos álbuns fotográficos do início do século. Revista Acervo, Rio de Janeiro, v.6, nº 1-2, p. 99-110, jan/dez 1993.

. O circuito social da fotografia: estudo de caso - II. In: FABRIS, Annateresa. (org.) Fotografia: usos e funções no século XIX. São Paulo: Editora da Universidade de São Paulo, 2008, p. 59- 82.

MAUAD, Ana Maria. Entre retratos e paisagens: modos de ver e representar no Brasil oitocentista. Revista Studium, n.15.

MUAZZE, Mariana. As memórias da Viscondessa: Família e poder no Brasil Império. Rio de Janeiro: Jorge Zahar Ed, 2008.

ROUILLE, Andre. A fotografia: entre documento e arte contemporânea. São Paulo: Editora Senac São Paulo, 2009.

VASQUEZ, Pedro Karp. O Brasil na fotografia oitocentista. São Paulo: Metalivros, 2003.

ZENHA, Celeste. O Brasil na produção das imagens impressas durante o século XIX: a paisagem como símbolo da nação. In: DUTRA, Eliana de Freitas e MOLLIER, Jean-Yves (org.). Política, nação e edição: o lugar dos impressos na construção da vida política. São Paulo: Annablume, 2006, p. 354-368. b 